\title{
Cholesteric Liquid-Crystalline Elastomers Prepared from Ionic Bis-Olefinic Crosslinking Units
}

\author{
Fan-Bao Meng, Bao-Yan ZhANG, ${ }^{\dagger}$ Qian-Yue LI, and Ji QI \\ The Research Centre for Molecular Science and Engineering, Northeastern University, \\ 110004, Shenyang, P. R. China
}

(Received October 25, 2004; Accepted January 13, 2005; Published April 15, 2005)

\begin{abstract}
A series of cyclosiloxane-based cholesteric LCEs were synthesized by using a LC monomer cholest5-en-3-ol(3 $\beta$ )-4-(2-propenyloxy)benzoate and an ionic divinyl monomer 2,2'-(1,2-ethenediyl)-bis[5-[(4-undecenoyloxy)phenyl]-azo]-benzenesulfonic acid. The polymers were prepared in a one-step reaction with ionic crosslinking contents ranging between mass content 0 and $11.8 \%$. Their chemical structures and liquid-crystalline properties were characterized by FT IR, ${ }^{1} \mathrm{H}$ NMR, DSC, POM and X-ray measurement. The effective crosslink density $\left(M_{\mathrm{c}}\right)$ was determined by swelling experiments in mixed buffer/organic solvent mixtures, using Brannon-Peppas models. All the polymers exhibit thermotropic LC properties and reveal cholesteric phase. With increase of ionic crosslinking component in the polymers, the melting behavior disappears and the temperature of clear point decreases. Reflection spectra of cholesteric mesophase of the series of polymers showed that the reflected wavelength becomes broad and shifts to long wavelength with increase of the ionic crosslinking component in the polymer systems.

[DOI 10.1295/polymj.37.277]
\end{abstract}

KEY WORDS Liquid-Crystalline Elastomer / Sulfonate Groups / Cholesteric Phase / Polysiloxane /

Slightly crosslinked liquid crystalline (LC) polymers that combine the properties of liquid crystalline phases and the elastic properties and form stability of polymeric networks are known as liquid crystalline elastomers (LCEs). They possess unique features originating from rubber elasticity, and the orientation of the mesogens can be controlled by mechanical forces as well as by electric and magnetic fields. As a result of these remarkable characteristics LCEs are promising materials for optoelectrical applications, including polarization halography, optical memory, integrated optical circuitry, and nonlinear optical generators. ${ }^{1,2}$

Research into cholesteric liquid-crystalline networks has expanded rapidly in recent years because they have outstanding optical properties. ${ }^{3,4}$ Cholesteric mesophases exhibit interesting optical properties such as the selective reflection of circular polarized light and an angular dependence of the reflected wavelength. If the reflected wavelength is in the visible range of the spectrum, the cholesteric phase appears colored. The formation of polymer networks with a cholesteric structure has attracted considerable interest because the helical structure of the cholesteric phase is permanently frozen-in and so the optical properties become temperature independent. ${ }^{5,6}$

Recently research has been extended to elastomers or networks having ionic and mesogenic sites in their chain. ${ }^{7}$ The introduction of the ionic species was found to affect the properties of the liquid-crystalline polymers. ${ }^{8}$ Ionic aggregates can play a role in physical crosslinking and provide an important and characteristic viscoelastic behavior of polymers. Strong ionic interactions between polymer molecules are known to significantly enhance mechanical properties. ${ }^{9}$ On the other hand, the incorporation of small concentration of ions into organic polymers has been shown to lead to microphase-separated ionic domains that influence greatly the properties of the polymers. ${ }^{10}$

We are interested in cholesteric liquid crystalline elastomers containing ionic groups. We select sulfonate groups as ionic units because they show excellent ionic properties with a little component and preserve liquid crystalline mesophase easily. One would like to know the fundamental link between ionic aggregation found in the networks and the behavior of liquid-crystalline phases. Furthermore, it is interest to investigate how the chemical crosslinking components and the physical ionic interactions modify liquid-crystalline structures of such kind of cholesteric networks.

In the present study, we prepared a series of cholesteric LCEs using chemical crosslinking agents containing sulfonate groups, which were cyclosiloxanebased materials. Their general structure is shown in Figure 1. Elastomers of this type may be readily prepared in a one-step reaction, in which both the mesogenic unit and an ionic divinyl monomer added to the polymer backbone. 


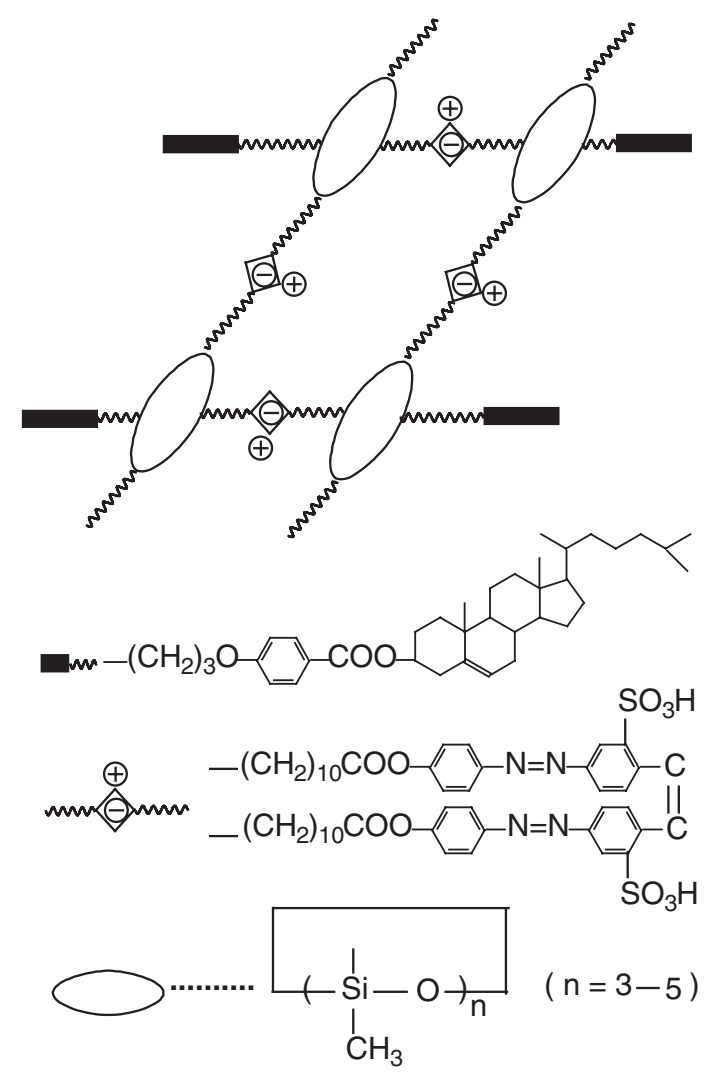

Figure 1. The general structure of the ionic elastamers.

\section{EXPERIMENTAL}

\section{Material and Measurements}

Brilliant yellow, 10-undecylenoic acid, cholesterol and pyridine were purchased from Beijing Chemical Co. Hexachloroplatinic acid hydrate, bromopropene, 4-hydroxy-benzoic acid, toluene and thionyl chloride were obtained from Shenyang Chemical Co. Cyclo(methylhydrogeno)siloxane (CMHS) $\left(M_{\mathrm{n}}=200-300\right)$ were obtained from Jilin Chemical Industry Company and used without any further purification. Pyridine was purified by distillation over $\mathrm{KOH}$ and $\mathrm{NaH}$ before using.

Fourier transform infrared spectroscopy (FT IR) of the synthesized polymers and monomers in solid state were obtained by the $\mathrm{KBr}$ method performed on a Nicolet 510P FT IR Spectrometer. ${ }^{1} \mathrm{H}$ NMR spectra $(300 \mathrm{MHz})$ were recorded on a Varian WH-90 spectrometer (Varian Associates, Palo Alto, CA). Ultraviolet-visible spectrophotometry was measured by PerkinElmer instruments Lambda 900. Reflection spectra of cholesteric mesophase was done by reflective light with beam's incident angle of $8^{\circ}$. Thermal transition properties were characterized by a NETZSCH Instruments DSC 204 at a heating rate of $10^{\circ} \mathrm{C} \mathrm{min}^{-1}$ under nitrogen atmosphere. Visual observation of liquid crystalline transitions under cross polarized light was made by a Leitz Laborlux S polar- izing optical microscope (POM) equipped with a THMS-600 heating stage. X-Ray measurements of the samples were performed using $\mathrm{Cu} \mathrm{K} \alpha \quad(\lambda=$ $1.542 \AA$ ) radiation monochromatized with a Rigaku DMAX-3A X-ray diffractometer.

\section{Synthesis of Monomers}

2,2'-(1,2-Ethenediyl)-bis[5-[(4-undecenoyloxy)phenyl]-azo]-benzenesulfonic acid. This ionic bis-olefinic crosslinking monomer was prepared according to previously reported synthetic method. ${ }^{11}$ The yield was $63 \%$. mp: $132^{\circ} \mathrm{C}$.

IR $\left(\mathrm{KBr}, \mathrm{cm}^{-1}\right): 3420(-\mathrm{OH}), 3080(=\mathrm{C}-\mathrm{H}), 2928$, $2856\left(\mathrm{CH}_{3}-\right.$ and $\left.-\mathrm{CH}_{2}-\right), 1755(\mathrm{C}=\mathrm{O}), 1590,1500$ (Ar-), $1199(\mathrm{C}-\mathrm{O}-\mathrm{C}), 1137,1078\left(\mathrm{~S}=\mathrm{O}\right.$ in $\left.-\mathrm{SO}_{3} \mathrm{H}\right)$.

${ }^{1} \mathrm{H}$ NMR $\left(\mathrm{CDCl}_{3}, \delta, \mathrm{ppm}\right): 11.30\left(\mathrm{~s}, 2 \mathrm{H},-\mathrm{SO}_{3} \mathrm{H}\right)$, 8.75-7.35 (m, 14H, Ar- $\underline{\mathrm{H}}), 6.95$ (s, 2H, $-\mathrm{C} \underline{\mathrm{H}}=\mathrm{C} \underline{\mathrm{H}}-$ ), 6.05-5.78 (m, 4H, $\left.\mathrm{CH}_{2}=\mathrm{CH}-\right), 5.20-5.10(\mathrm{~m}, 2 \mathrm{H}$, $\mathrm{CH}_{2}=\mathrm{C} \underline{\mathrm{H}}-$ ), 3.96-3.86 (t, $4 \mathrm{H},-\mathrm{C}_{2} \mathrm{COO}-$ ), 2.98$2.69\left(\mathrm{~m}, 4 \mathrm{H},=\mathrm{CH}-\mathrm{CH}_{2}-\right), 2.32-1.49(\mathrm{~m}, 24 \mathrm{H}$, $\left.-\mathrm{CH}_{2}-\right)$.

Cholest-5-en-3-ol(3 $\beta$ )-4-(2-propenyloxy)benzoate. This liquid crystalline monomer was prepared according to previously reported synthetic method. ${ }^{12}$ The yield was $70 \%$. mp: $107^{\circ} \mathrm{C}$.

IR $\left(\mathrm{KBr}, \mathrm{cm}^{-1}\right)$ : $3051(=\mathrm{C}-\mathrm{H}), 2971-2854\left(-\mathrm{CH}_{3}\right.$, $\left.-\mathrm{CH}_{2}-\right), 1706(\mathrm{C}=\mathrm{O}), 1608,1511(\mathrm{Ar}-), 1277,1172$ $(\mathrm{C}-\mathrm{O}-\mathrm{C})$.

${ }^{1} \mathrm{H}$ NMR $\left(\mathrm{CDCl}_{3}, \delta, \mathrm{ppm}\right): 7.98-6.92(\mathrm{~m}, 4 \mathrm{H}, \mathrm{Ar}-$ $\underline{\mathrm{H}}), 6.02\left(\mathrm{~m}, 2 \mathrm{H}, \mathrm{C}_{2}=\mathrm{CH}-\right), 5.36(\mathrm{~m}, 1 \mathrm{H},=\mathrm{C} \underline{\mathrm{H}}-$ in cholesteryl), 5.18-4.69 (m, $1 \mathrm{H}, \mathrm{CH}_{2}=\mathrm{C}-$ -$), 4.47$ (t, $\left.2 \mathrm{H},-\mathrm{OC}_{2}-\right), 2.03-0.67$ (m, $43 \mathrm{H}$, cholesteryl- $\left.\underline{\mathrm{H}}\right)$.

\section{Synthesis of Elastomers}

For synthesis of polymers P1-P7, the same method was adopted. The polymerization experiments were summarized in Table I. The synthesis of polymer P4 was given as an example. 2,2'-(1,2-Ethenediyl)-bis[5-[(4-undecenoyloxy)phenyl]-azo]-benzenesulfonic acid $(0.14 \mathrm{~g}, 0.15 \mathrm{mmol}$, monomer A) was dissolved in $100 \mathrm{~mL}$ of dry, fresh distilled toluene. To the

Table I. Feed and polymerization of the series of polymers

\begin{tabular}{cccccc}
\hline & \multicolumn{4}{c}{ Feed } & A content $^{\mathrm{a}}$ \\
\cline { 2 - 5 } Sample & $\begin{array}{c}\text { CMHS } \\
(\mathrm{mmol})\end{array}$ & $\begin{array}{c}\mathrm{A} \\
(\mathrm{mmol})\end{array}$ & $\begin{array}{c}\mathrm{B} \\
(\mathrm{mmol})\end{array}$ & $\begin{array}{c}\text { (wt. \% }) \\
(\%)\end{array}$ \\
\hline P1 & 1.0 & 0 & 4.00 & 0 & 92 \\
P2 & 1.0 & 0.05 & 3.90 & 1.9 & 92 \\
P3 & 1.0 & 0.10 & 3.80 & 3.9 & 93 \\
P4 & 1.0 & 0.15 & 3.70 & 6.0 & 90 \\
P5 & 1.0 & 0.20 & 3.60 & 7.8 & 91 \\
P6 & 1.0 & 0.25 & 3.50 & 9.8 & 93 \\
P7 & 1.0 & 0.30 & 3.40 & 11.8 & 90 \\
\hline
\end{tabular}

${ }^{\mathrm{a}}$ mass content of monomer $\mathrm{A}$ in the polymer systems. 
stirred solution, cholest-5-en-3-ol( $3 \beta$ )-4-(2-propenyloxy)benzoate ( $2.02 \mathrm{~g}, 3.70 \mathrm{mmol}$, monomer B), cyclo(methylhydrogeno)siloxane (CMHS, $0.24 \mathrm{~g}, 1.0 \mathrm{mmol}$ ) and $2 \mathrm{~mL}$ of $\mathrm{H}_{2} \mathrm{PtCl}_{6} / \mathrm{THF}(0.50 \mathrm{~g}$ hexachloroplatinic acid hydrate dissolved in $50 \mathrm{~mL}$ tetrahydrofuran THF) were added and heated under nitrogen and anhydrous conditions at $65^{\circ} \mathrm{C}$ for $72 \mathrm{~h}$. The solution was cooled and poured into $100 \mathrm{~mL}$ methanol. After filtration and evaporation of the solvent, the product was dried at $80^{\circ} \mathrm{C}$ for $2 \mathrm{~h}$ under vacuum to obtain $2.16 \mathrm{~g}$ of polymer in the yield of $90 \%$.

IR $\left(\mathrm{KBr}, \mathrm{cm}^{-1}\right): 3405(-\mathrm{OH}), 2960-2850\left(\mathrm{CH}_{3}-\right.$ and $\left.-\mathrm{CH}_{2}-\right), 1710(\mathrm{C}=\mathrm{O}), 1606,1510$ (phenyl), $1274(\mathrm{Si}-\mathrm{C}), 1255(\mathrm{C}-\mathrm{O}), 1168(\mathrm{~S}=\mathrm{O}) .1114-1011$ (Si-O-Si).

\section{RESULTS AND DISCUSSION}

\section{Effective Crosslink Density}

It is necessary to measure the effective crosslink density (or the molecular weight between the crosslink points $\left(M_{\mathrm{c}}\right)$ ) in order to characterize the crosslinking degree. We determine the effective crosslink density by swelling experiments as depicted in our previous study. ${ }^{11}$ We used Brannon-Peppas equation to describe this ionic contribution term for both ionic systems: ${ }^{13}$

$$
\begin{aligned}
V_{1}[ & \left.K_{\mathrm{a}} /\left(10^{-\mathrm{pH}}+K_{\mathrm{a}}\right)\right]^{2}\left(V_{2 \mathrm{~S}} / V\right)^{2} / 4 I \\
= & {\left[\ln \left(1-V_{2 \mathrm{~S}}\right)+V_{2 \mathrm{~S}}+\chi V_{2 \mathrm{~S}}{ }^{2}\right] } \\
& +\left[V_{1} /\left(V M_{\mathrm{c}}\right)\right]\left(1-2 M_{\mathrm{c}} / M_{\mathrm{n}}\right) \\
& \times V_{2 \mathrm{r}}\left[\left(V_{2 \mathrm{~S}} / V_{2 \mathrm{r}}\right)^{1 / 3}-\left(V_{2 \mathrm{~S}} / V_{2 \mathrm{r}}\right) / 2\right]
\end{aligned}
$$

where $M_{\mathrm{c}}$ is the number average molecular weight between crosslinks; $\chi$ is Flory polymer-swelling agent interaction parameter; $V_{1}$ is the molar volume of the swelling agent; $I$ is the ionic strength of the swelling medium; $K_{\mathrm{a}}$ is the dissociation constant of ionizable groups on polymer; $V$ is the specific volume of dry polymer; $M_{\mathrm{n}}$ is the number-average molecular weight of the linear macromolecules before crosslinking; $V_{2 S}$ is the volume fraction of polymer network after swelling and $V_{2 \mathrm{r}}$ is the polymer volume fraction after crosslinking but before swelling.

Using eq 1, we can obtain a linear relation with $\chi$ and $M_{\mathrm{c}}$ values as the intercept and inverse slope, respectively, as expressed by

$$
A=\chi+B / M_{\mathrm{c}}
$$

The volume fraction of polymer network $V_{2 S}$ was calculated as

$$
V_{2 \mathrm{~S}}=1 / Q
$$

The equilibrium/swelling ratio of networks was determined gravimetrically through the following equation:

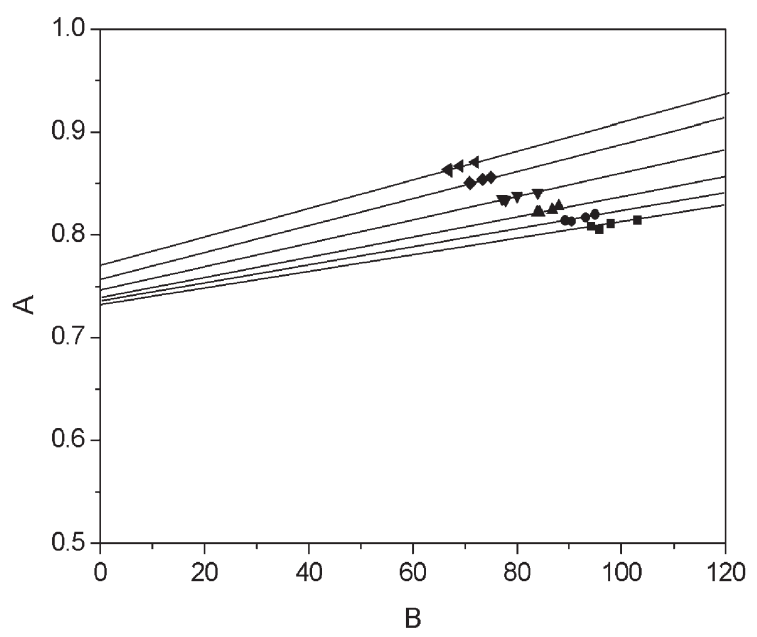

Figure 2. Determination of $\chi$ and $M_{\mathrm{c}}$ values of polymers from

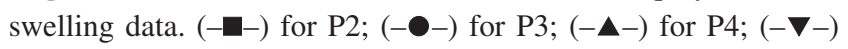
for P5; (-४) for P6; (-४-) for P7.

$$
Q=1+\left(W_{2} / W_{1}-1\right) \rho_{\mathrm{p}} / \rho_{\mathrm{s}}
$$

Where $Q$ is the swelling ratio of networks by volume; $W_{1}$ is weight of the network before swelling; $W_{2}$ is the weight of the network at equilibrium swelling; $\rho_{\mathrm{p}}$ and $\rho_{\mathrm{s}}$ are densities of polymer and solvent, respectively.

For these ionic elastomers, we also choose dimethyl sulfoxide (DMSO)/buffer as swelling solvent. Some of the information about the swelling experiments of the elastomers was collected in Table II. The relevant experimental parameters to be used are as follows: $I=0.1 \mathrm{M} ; \quad V_{1}=28.7 \mathrm{~cm}^{3} / \mathrm{mol} ; M_{\mathrm{n}}=2480 ; \mathrm{p} K_{\mathrm{a}}=$ 6.3. The parameters $V$ and $V_{2 \mathrm{r}}$ are calculated by using density values of the polymers. By using the values of $A$ and $B$, it is possible to establish the corresponding linear relationships about $\chi$ and $1 / M_{\mathrm{c}}$, as shown in Figure 2. The respective $\chi$ and $M_{\mathrm{c}}$ values were determined via linear regression analysis of the lines given in Figure 2, which are listed in Table II.

\section{Liquid-Crystalline Behavior}

All the polymers were studied by DSC, X-ray and observed by polarizing microscopy. The thermal behaviors are included into Table III, and Figure 3 displays the DSC thermograms of all the polymers synthesized.

In the DSC thermogram, some of the polymers (P1 and P2) display three kinds of phase transition behavior corresponding to glass transition, melting point and clear point, but the others show glass transition and clear point. In Figure 3, with increase of crosslinking groups in the polymers $\mathrm{P} 1-\mathrm{P} 7$, the temperature of clear point decrease, while the glass transition temperature decrease from $\mathrm{P} 1$ to $\mathrm{P} 4$ and increase from $\mathrm{P} 4$ to $\mathrm{P} 7$, suggesting a minimum value.

All the polymers exhibit thermotropic LC proper- 
Table II. Some swelling properties of the polymers

\begin{tabular}{|c|c|c|c|c|c|c|c|c|c|}
\hline \multirow{2}{*}{ Sample } & \multirow{2}{*}{$\begin{array}{l}\text { Density } \\
\left(\mathrm{g} / \mathrm{cm}^{3}\right)\end{array}$} & \multirow{2}{*}{$\begin{array}{c}V \\
\left(\mathrm{~cm}^{3} / \mathrm{g}\right)\end{array}$} & \multirow{2}{*}{$V_{2 \mathrm{r}}$} & \multicolumn{4}{|c|}{$V_{2 S}$} & \multirow{2}{*}{$\chi$} & \multirow{2}{*}{$\begin{array}{c}M_{\mathrm{c}} \\
(\mathrm{g} / \mathrm{mol})\end{array}$} \\
\hline & & & & $\mathrm{pH} 1.9$ & pH 3.5 & $\mathrm{pH} 4.5$ & $\mathrm{pH} 4.8$ & & \\
\hline P1 & 1.240 & 0.806 & 1.0 & - & - & - & - & - & - \\
\hline $\mathrm{P} 2$ & 1.242 & 0.805 & 0.998 & 0.452 & 0.450 & 0.446 & 0.440 & 0.73 & 1250 \\
\hline P3 & 1.246 & 0.803 & 0.996 & 0.465 & 0.462 & 0.458 & 0.453 & 0.73 & 1180 \\
\hline $\mathrm{P} 4$ & 1.248 & 0.801 & 0.994 & 0.480 & 0.479 & 0.476 & 0.472 & 0.74 & 1060 \\
\hline P5 & 1.251 & 0.799 & 0.991 & 0.501 & 0.499 & 0.496 & 0.493 & 0.75 & 890 \\
\hline P6 & 1.256 & 0.796 & 0.988 & 0.523 & 0.521 & 0.518 & 0.515 & 0.76 & 760 \\
\hline P7 & 1.259 & 0.794 & 0.985 & 0.539 & 0.537 & 0.534 & 0.531 & 0.77 & 650 \\
\hline
\end{tabular}

Table III. Thermal properties and the maximum reflected wavelengths of the polymers

\begin{tabular}{|c|c|c|c|c|}
\hline \multirow[b]{2}{*}{ Sample } & \multicolumn{3}{|c|}{ DSC } & \multirow{2}{*}{$\begin{array}{l}\lambda_{\text {ref }^{\mathrm{a}}} \\
(\mathrm{nm})\end{array}$} \\
\hline & $\begin{array}{c}T_{\mathrm{g}} \\
\left({ }^{\circ} \mathrm{C}\right)\end{array}$ & $\begin{array}{c}T_{\mathrm{m}} \\
\left({ }^{\circ} \mathrm{C}\right)\end{array}$ & $\begin{array}{c}T_{\mathrm{c}} \\
\left({ }^{\circ} \mathrm{C}\right)\end{array}$ & \\
\hline P1 & 61.1 & 110.1 & 229.3 & 326 \\
\hline $\mathrm{P} 2$ & 52.6 & 122.5 & 229.2 & 329 \\
\hline P3 & 50.2 & - & 224.8 & 343 \\
\hline $\mathrm{P} 4$ & 39.7 & - & 225.7 & 348 \\
\hline P5 & 44.3 & - & 216.8 & 349 \\
\hline P6 & 41.8 & - & 213.2 & 350 \\
\hline P7 & 63.1 & - & 204.0 & $356-500$ \\
\hline
\end{tabular}

${ }^{a}$ The maximum reflected wavelength characterized by PerkinElmer instruments Lambda 900.

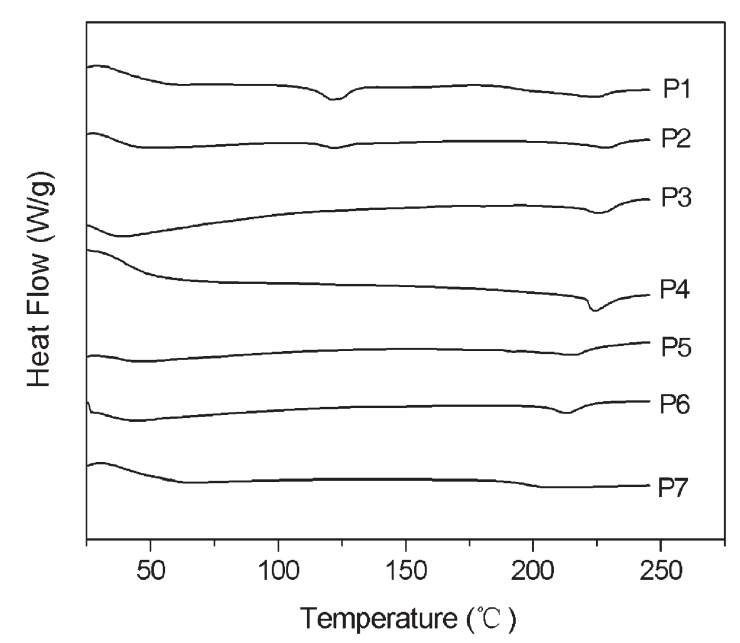

Figure 3. DSC thermograms of the series of polymers (on the first heating $\left.\left(10^{\circ} \mathrm{C}\right) / \mathrm{min}\right)$.

ties and reveal cholesteric phase. Mesophase identification has been accomplished by X-ray measurement and polarized optical microscopic observation. The optical textures of the polymers were investigated via POM with cold and hot stages under a nitrogen atmosphere. All the polymers showed similar cholesteric phase textures on heating and cooling cycles. The representative textures were shown in Figure 4. For polymer P4, when it was heated from the room temperature, viewing field became bright and a grand- jean texture (see Figure 4a) appeared. When it was heated to $185^{\circ} \mathrm{C}$, the typical oily-streak texture gradually appeared (see Figure 4b), and the selective reflection color changed from red to blue with increasing temperature; the texture disappeared at $226^{\circ} \mathrm{C}$. When the isotropic state was cooled to $219^{\circ} \mathrm{C}$, the broken focal-conic texture appeared (see Figure 4c). When a mechanical force was superimposed on the sample, such as slight shearing, the melt caused macroscopic orientation of the cholesteric domains, and the broken focal-conic texture immediately transformed into the oily-streak texture (see Figure 4d), which is typical of cholesteric liquid crystals.

The cholesteric mesophase has also been confirmed by X-ray diffraction. Figure 5 shows the X-ray diffraction diagrams of samples P2, P4 and P6. A broad diffraction peak around $2 \theta=17^{\circ}$ is observed for $\mathrm{P} 2$, P4 and P6, which suggests the average distance of $5 \AA$ between two neighbor LC molecules within the layers of the mesophase. The diffraction peak around $2 \theta=10^{\circ}$ corresponding $d$ spacing $9.4 \AA$ suggests the ordered structure due to the ionic aggregates in the polymer systems.

Both ionic groups and chemical crosslinking may influence the liquid-crystalline behavior of the elastomers.

The glass-transition temperature $\left(T_{\mathrm{g}}\right)$ of ionic LCEs is influenced by some factors such as the main-chain structures, side-chain groups and crosslinking component. On the one hand, some factors make $T_{\mathrm{g}}$ decrease. The majority of polymers based on siloxane chains are atactic, and the glass-transition temperature may be considered as a measure of the backbone flexibility. Liquid crystalline polymers are most commonly composed of flexible and rigid moieties, thus the nature of the side-group also influences $T_{\mathrm{g}}$. For the polymer $\mathrm{P} 1$, the rigid moieties containing cholesteryl groups made it possess relatively high $T_{\mathrm{g}}$ due to sterically hindered effect. With increase of the crosslinking component in the polymer systems, the rigid moieties decrease. Furthermore, because of flexible space groups between the ionic crosslinking component and the main-chain structures, the backbone flexibility 


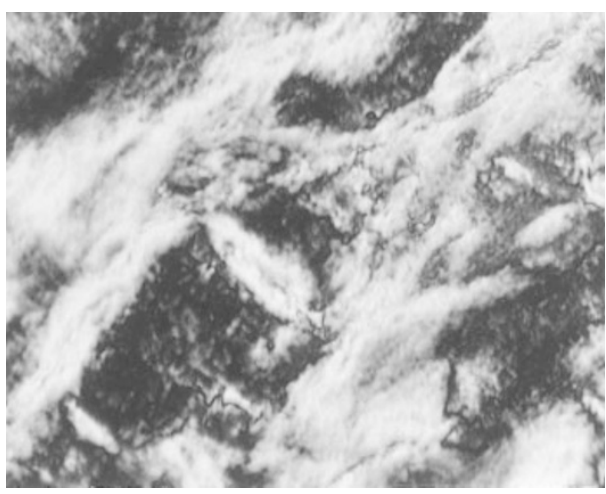

(a)

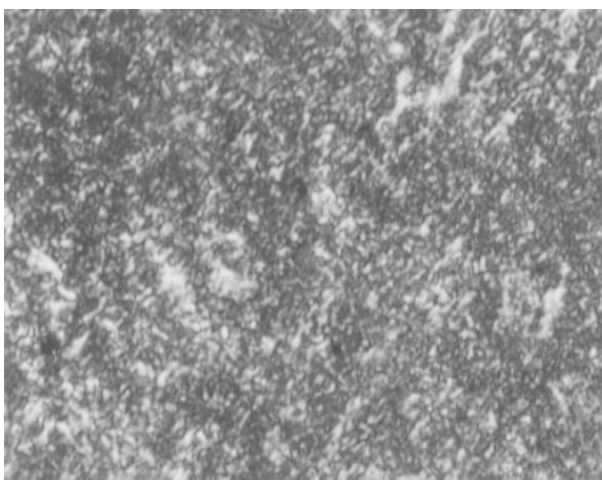

(c)

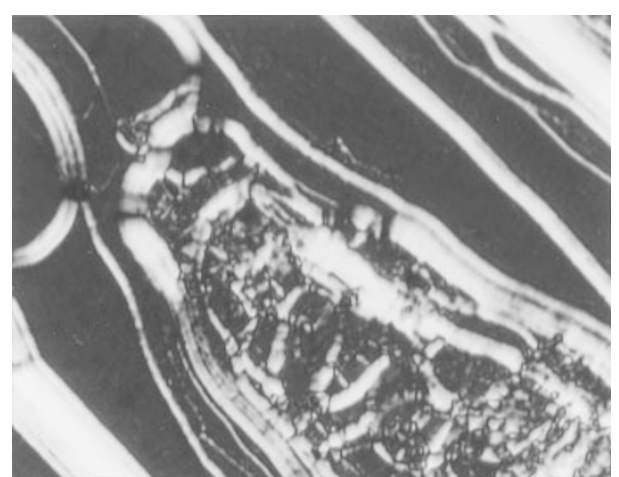

(b)

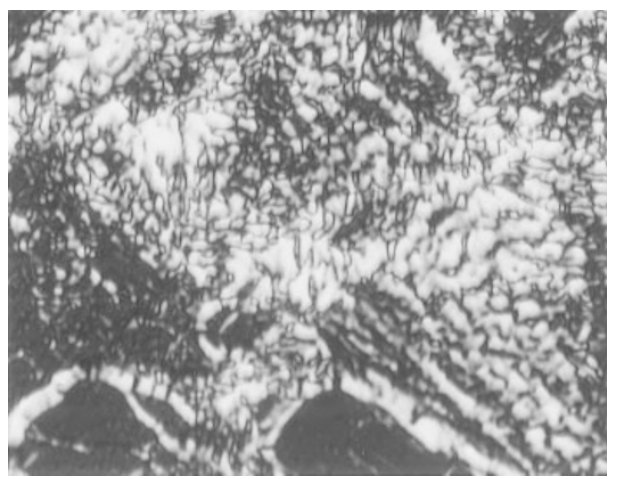

(d)

Figure 4. Optical textures of the polymer P4 (200×): (a) grandjean texture on heating to $123^{\circ} \mathrm{C}$, (b) oily-streak texture on heating to $185^{\circ} \mathrm{C}$, (c) broken focal-conic texture on cooling to $219^{\circ} \mathrm{C}$, and (d) oily-streak texture on cooling to $201^{\circ} \mathrm{C}$.

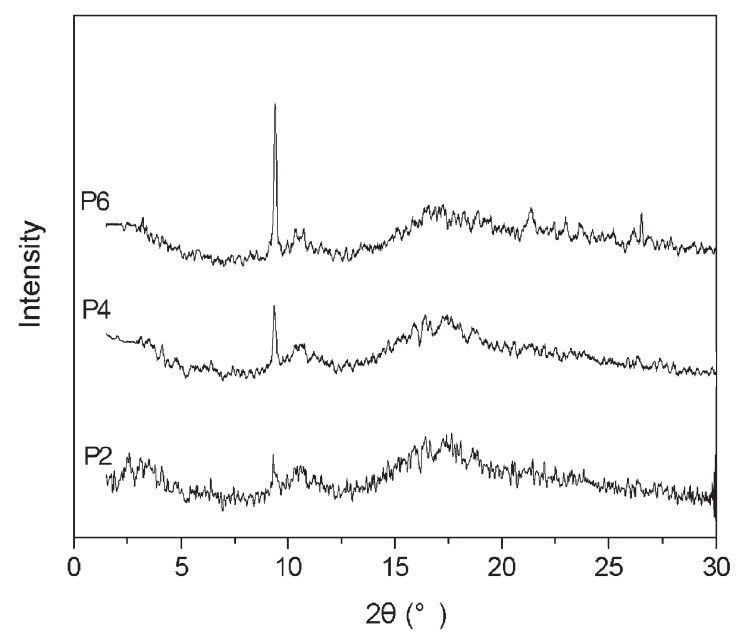

Figure 5. X-Ray diffraction diagrams of the polymers P2, P4 and $\mathrm{P} 6$.

increases. These reasons illustrate the decrease of $T_{\mathrm{g}}$ from P1 to P4. On the other hand, some factors make $T_{\mathrm{g}}$ of these kinds of LCEs increase. It is well-known that the incorporation of ionic groups leads to an elevated $T_{\mathrm{g}}$ for ionomers based on amorphous, flexible polymers. ${ }^{14}$ For ionomers with a relatively low proportion of ionic units, two-phase behavior is frequently observed due to ionic aggregation in a relatively nonpolar matrix, with consequent reduction in mobility of neighboring nonpolar regions. ${ }^{15}$ Furthermore, chemical crosslinking imposes additional constrains on the segmental motion of polymer chains, and might be expected to raise the glass-transition temperatures. ${ }^{16}$ Therefore, when there are enough ionic crosslinking component in the network systems, the chemical crosslinking and physical crosslinking (originated from ionic groups) would be dominant, leading to increase of $T_{\mathrm{g}}$. These reasons explain the increase of $T_{\mathrm{g}}$ from P4 to P7. In consideration of the two cases, the $T_{\mathrm{g}}$ values shown in Table III seem to have the minimum value depending of the LCE composition.

Because liquid crystalline polymers are most commonly composed of flexible and rigid moieties, selfassembly and nanophase separation into specific micro-structures frequently occur due to geometric and chemical dissimilarity of the two moieties. For the polymers P1 and P2 which contain less ionic crosslinking component, the organization of the longer hard segments is easer, resulting in a higher degree of crystallinity of the hard phase. These results demonstrate the melting behavior in P1 and P2. For other polymers from $\mathrm{P} 3$ to $\mathrm{P} 7$ which contain more ionic crosslinkeng component, the crosslinking units may act as a non-mesogenic diluent and destabilize the 
phase in a manner analogous to the freezing-point depression in liquids. Furthermore, Chemical crosslinks in polymers could introduce inhomogeneity in the networks in the form of clustered hard segments. Therefore, the physical and chemical crosslinking induced by the ionic bis-olefinic units destroy the degree of order, leading to absence of melting behaviors.

Because of physical nondirectional crosslinking ionic action of the ionic groups and the chemical crosslinking agents in mesogenic phase, the ionic crosslinking units may act as a non-mesogenic diluent and destabilize the phase. As a result, the mesophase of the liquid crystalline polymers is easy to transit to isotropic phase. Therefore, the temperature of clear point $\left(T_{\mathrm{c}}\right)$ decreases with increase of the ionic crosslinking groups. These results also demonstrate the behavior of mesophase texture.

\section{Reflection Spectra of Cholesteric Mesophase}

Cholesteric mesophases exhibit interesting optical properties such as the selective reflection of circular polarized light and an angular dependence of the reflected wavelength. If the reflected wavelength is in the visible range of the spectrum, the cholesteric phase appears colored. The wavelength, $\lambda_{\max }$, of reflected light from a cholesteric sample is given by

$$
\lambda=n P \sin \varphi
$$

where $n$ is the average refractive index of the liquid crystalline phase, $P$ is the pitch height of the helicoidal arrangement, and $\varphi$ is the incident angle of beam. The helical pitch $P$ depends on many factors such as the concentration of the chiral substance, the temperature and an external field of mechanical, electric or magnetic origin, etc. ${ }^{17}$

The reflected wavelengths of the samples P1-P7 were characterized by PerkinElmer instruments Lambda 900 when the samples were heated at their mesophases (exactly $128.0^{\circ} \mathrm{C}$ ) without any external field, which were listed in Table III. Figure 6 shows the maximum reflected wavelength of $\mathrm{P} 1, \mathrm{P} 4$ and $\mathrm{P} 7$ at 326,348 and $356-500 \mathrm{~nm}$, respectively. It is shown that the maximum reflection bands become broad from P1 to P7 with increase of ionic rosslinking component in the samples. Furthermore, the data mean that the reflected wavelength shift to long wavelength from P1 to P7 with increase of the ionic crosslinking component in the polymer systems, suggesting the helical pitch $P$ become longer according eq 5. These results are because the fact that the helical structure is partially disrupted due to the interaction of ionic groups and the constraint of chemical crosslinking agents. Consequently, the pitch of the helical structure would become longer with increase of the ionic crosslinking component.

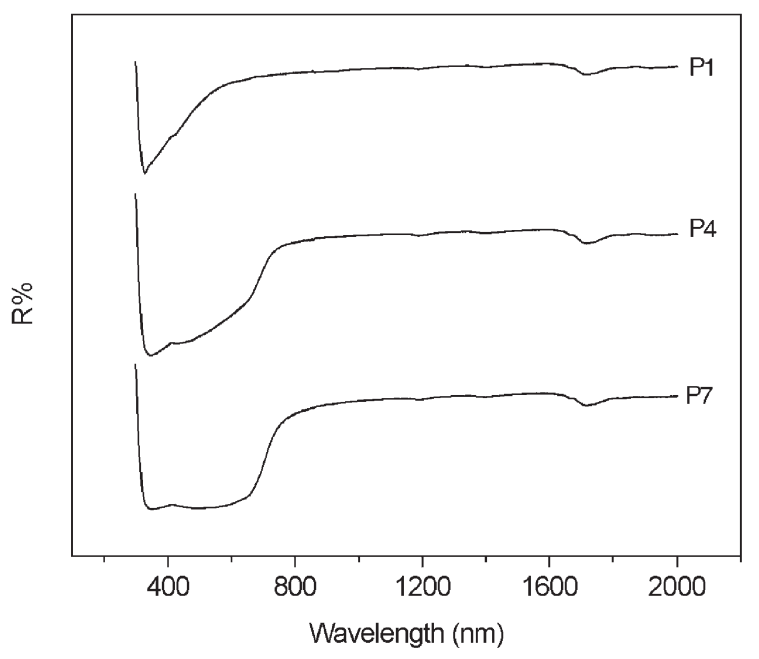

Figure 6. The reflected wavelengths of P1, P4 and P7 at $128.0^{\circ} \mathrm{C}$ without any external field.

\section{CONCLUSIONS}

A series of cyclosiloxane-based cholesteric LCEs were synthesized by using a LC monomer cholest-5en-3-ol(3 $\beta$ )-4-(2-propenyloxy)benzoate and an ionic divinyl monomer 2,2'-(1,2-ethenediyl)-bis[5-[(4-undecenoyloxy)phenyl]-azo]-benzenesulfonic acid. The polymers were prepared in a one-step reaction with ionic crosslinking contents ranging between 0 and $11.8 \mathrm{wt} \%$. Their chemical structures and liquid-crystalline properties were characterized by FT IR, ${ }^{1} \mathrm{H}$ NMR, DSC, POM and X-ray measurement. We have studied the elastomers with the help of swelling experiments to determine the effective crosslink density $\left(M_{\mathrm{c}}\right)$. Ionic polymer networks in aqueous solutions yield a more complicated situation than that of homogeneous networks. We employed Brannon-Peppas expression instead of Flory-Rehner models. The variety of network structures obtained by varying the ionic crosslinking contents leads to different swelling properties in mixed buffer/organic solvent mixtures.

All the polymers exhibit thermotropic LC properties and reveal cholesteric phase. With increase of ionic crosslinking component in the polymers, the melting behavior disappears and the temperature of clear point decreases. Liquid-crystal mesophase region of the polymers become narrow with increasing ionic crosslinking content. Both ionic groups and chemical crosslinking may influence the liquid-crystalline behavior of the elastomers.

Reflection spectra of cholesteric mesophase of the series of polymers showed that the reflected wavelength becomes broad and shifts to long wavelength with increase of the ionic crosslinking component in the polymer systems, suggesting that helical pitch $P$ become long. 
Acknowledgment. The authors are grateful to National Natural Science Fundamental Committee of China and HI-Tech Research and development program (863) of China and National Basic Research Priorities Program (973) of China, Science and Technology Research Major Project of Ministry of Education of China, and Specialized Research Fund for the Doctoral Program of Higher Education, and the Science and Technology Department of Liaoning Province, China (Fund No. 20032025) for financial support of this work.

\section{REFERENCES}

1. E. Gebhard and R. Zentel, Macromol. Chem. Phys., 201, 902 (2000).

2. J. Bonet, L. Callau, J. Reina, M. Galia, and V. Cadiz, J. Polym. Sci., Part A: Polym. Chem., 40, 3883 (2002).

3. M. A. Espinosa, V. Cadiz, and M. Galia, J. Polym. Sci., Part A: Polym. Chem., 39, 2847 (2001).

4. B. Y. Zhang, J. S. Hu, Y. G. Jia, and B. G. Du, Macromol. Chem. Phys., 204, 2123 (2003).

5. A. Stohr and P. Strohriegl, Macromol. Chem. Phys., 199, 751 (1998).
6. T. Pfeuffer, K. Kurschner, and P. Strohriegl, Macromol. Chem. Phys., 200, 2480 (1999).

7. F. B. Meng, B. Y. Zhang, L. M. Liu, and B. L. Zang, Polymer, 44, 3935 (2003).

8. B. Y. Zhang and R. A. Weiss, J. Polym. Sci., Part A: Polym. Chem., 30, 91 (1992).

9. E. B. Barmatov, D. A. Pebalk, M. V. Barmatova, and V. P. Shibaev, J. Polym. Sci., Part A: Polym. Chem., 39, 3953 (2001).

10. P. Y. Vuillaume, J. C. Galin, and C. G. Bazuin, Macromolecules, 34, 859 (2001).

11. B. Y. Zhang, F. B. Meng, B. L. Zang, and J. S. Hu, Macromolecules, 36, 3320 (2003).

12. N. W. Adms, J. S. Bradshaw, J. M. Bayona, K. E. Markkles, and M. E. Lee, Mol. Cryst. Liq. Cryst. Sci., 147, 43 (1987).

13. L. Brannon-Peppas and N. A. Peppas, Chem. Eng. Sci., 46, 715 (1991).

14. N. A. Plate and V. P. Shibaev, J. Polym. Sci., Macromol. Rev., 8, 117 (1974).

15. J. F. Gohy, R. Jerome, G. V. Bossche, and R. Sobry, Macromol. Chem. Phys., 199, 1791 (1998).

16. Y. Ikeda and T. Yonezawa, Polymer, 38, 3229 (1997).

17. P. Sikorski, S. J. Cooper, D. Edward, T. Atkins, G. Jaycox, and O. Vog, J. Polym. Sci., Part A: Polym. Chem., 36, 1855 (1998). 